Itinerarios culturales y rutas turístico-culturales 14

\title{
Uso y abuso de medios interpretativos en los itinerarios culturales
}

Renee Sivan. Conservadora jefe del Museo de la Historia de Jerusalén (Israel)

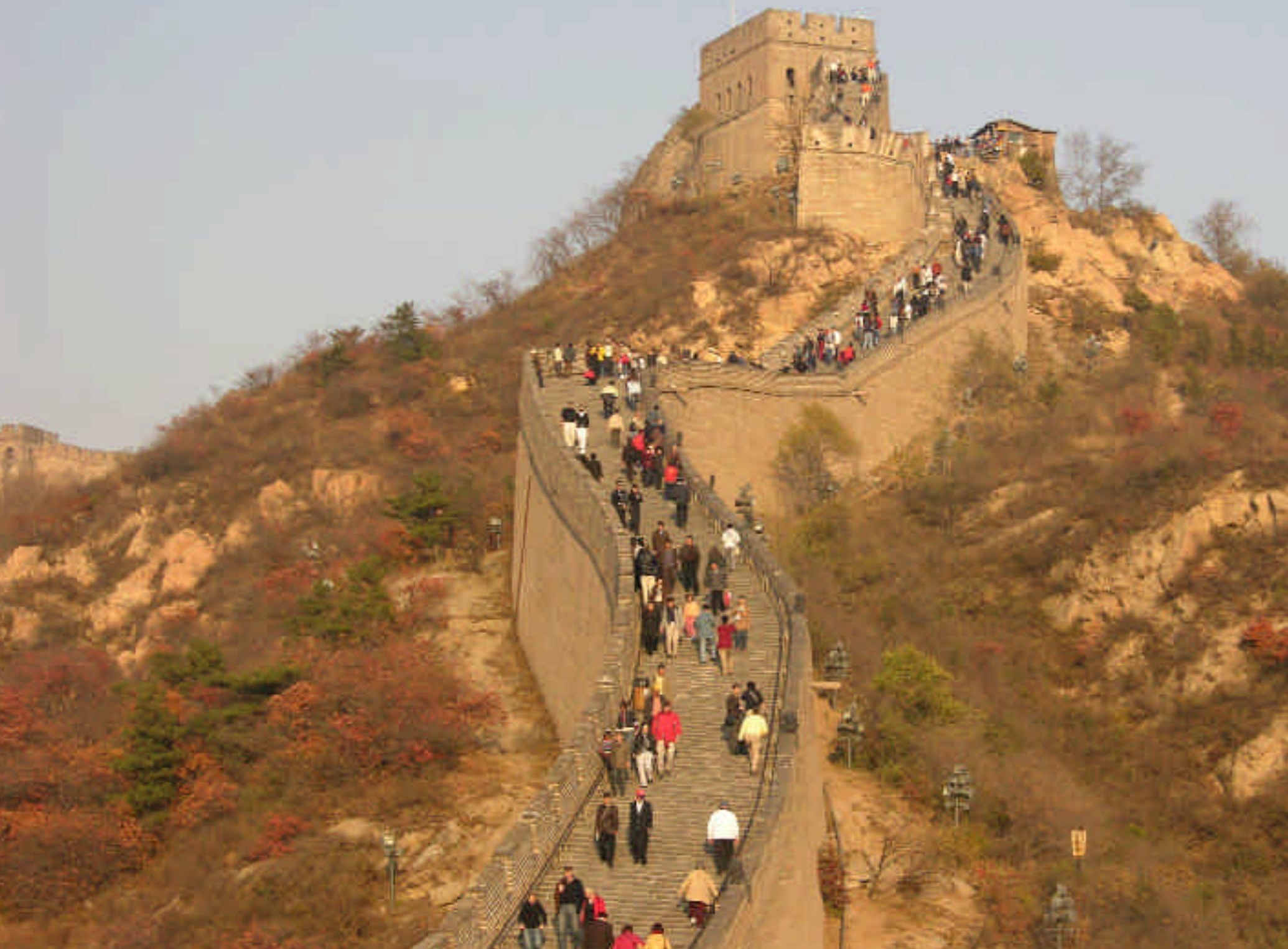


Quién no ha soñado con hacer la ruta de Marco Polo, navegar y navegar hasta los confines de China y volver con una naranja en la mano, un plato de espaguetis y proclamar a los cuatro vientos que yo también lo hice. Algunos de nosotros hicimos la Ruta Andina, el Camino de Santiago; incluso la Ruta de la Seda, que hasta no hace tantos años, anteriores a los conflictos sangrientos en Afganistán, no era un sueño sino algo real y factible.

Otra fantasía que, por razones políticas, no puede convertirse en realidad es la ruta de las especias, un camino mítico por el cual los Nabateos, los señores del desierto, transportaban incienso y mirra, las preciadas especies aromáticas necesarias para el servicio en el Templo del Rey Salomón y codiciadas por la aristocracia romana, camino que parte de lo que es hoy el Yemen, pasando por Arabia Saudita, Petra en Jordania, atraviesa el desierto del Negev en Israel y llega a la costa Palestina. Un camino multinacional como la ruta de la seda y muchos otros.

El concepto de Ruta no sólo inspiraba los espíritus sino que permitía soñar y descubrir, puede que fuera curiosidad, 0 tal vez un romanticismo sincero. Hacer el camino andino o el de Santiago (no sólo para los creyentes) superaba el quehacer turístico; es aún parte de una voluntad especial, una aventura por encima del nivel de un paseo, una actividad que nos transportaba a mundos lejanos, parte de un patrimonio que tal vez podríamos definir como mitológico. La ruta no es un mero itinerario: el esfuerzo físico, la preparación espiritual y la expectativa la convierten en algo muy distinto, algo por lo cual vale la pena sacrificarse ¿No es maravilloso, acaso, poder revivir el mismo camino que recorrieron nuestros ancestros?

Q Vista general de la Gran Muralla en el tramo de Badaling. Con Asia Central bajo control de la dinastía Han, se establecieron las legendarias Rutas de la Seda. Los comerciantes no podían llegar a sus destinos sin pasar a través de la Gran Muralla / Víctor Fernández Salinas
Podría pensarse que los valores mítico-patrimoniales han desaparecido. Una Ruta, hoy en día, es apenas un sinónimo de itinerario turístico. Baste mencionar las rutas del vino en Francia, California o Sudáfrica, la ruta de los pueblos blancos en Andalucía, la Garden Route en Sudáfrica, la ruta Maya de Guatemala y Belize y muchas otras que forman parte del ocio teledirigido. Rutas que suenan mas a transacción económica que a imagen patrimonial, sin por ello menoscabar su valor cultural.

Como todo en nuestro mundo global y "moderno" también nos inventamos recorridos a yacimientos arqueológicos, visibles o invisibles, o sitios de interés turístico con sabor cultural (natural o histórico). Aquellos lugares que tienen una temática común, que se encuentran en un espacio geográfico determinado y tienen rasgos similares son lo que hoy denominamos red, un término tomado de las carreteras o del mundo cibernético. Los fines son obvios: queremos dar a conocer el patrimonio y a la vez tener beneficio económico-social, a veces cuando bien organizados también tienen ventajas administrativas.

Nuestras ansias de dar a conocer, divulgar y conservar to do nos lleva a veces a exagerar, no basta la publicación común o el sitio virtual que provee la información relevante u otros sistemas de comunicación. Debemos también dejar una marca física in situ. Nos reinventamos el sitio, manipulamos la historia, reacondicionamos o trazamos caminos imaginarios, no siempre con el toque deseado y sucede que, a veces, perdemos el sabor natural, aquel que da a la ruta-red una imagen casi real, 0 creamos caminos que nadie usa. Pero más que nada nos gustan los centros de interpretación. A veces necesarios y fundamentales para la divulgación del patrimonio, otras simples tiendas Mac Donalds: el mismo pan, los mismos ingredientes y, como sucede con los Mac Donalds, el edificio cambia. Es así como la red pierde su valor primordial y se convierte en la red de los centros, el Mac Donald del patrimonio. La proliferación de centros de interpretación o divulga- 
X Machu Picchu (Cusco, Perú). El Camino Inca a Machu Picchu es actualmente el destino de turismo de aventura más importante de Latinoamérica y uno de los más reconocidos en el ámbito mundial / Víctor Fernández SALINAS

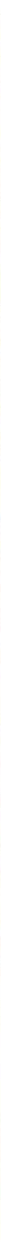

\author{
¿No es maravilloso, acaso, poder \\ revivir el mismo camino que \\ recorrieron nuestros ancestros?
}

ción, como quiera que se llamen, parecería ser la fiebre aviaria del patrimonio. Los centros no son lo principal, no deberían surgir a priori pero comienzan a ser solicitados y admirados por los planificadores turísticos que necesitan productos que vender y los políticos algo que inaugurar. Quien no remodela o construye un edificio con su sala de exposición, sala de proyección, lugar de investigación, tienda y cafetería no se siente digno de pertenecer a la familia del patrimonio cultural. Esos centros de interpretación creados sólo porque es bon ton o buen real no son más que elefantes blancos que producen efecto contrario al deseado.

La decisión política a priori de un centro aquí o allí donde los temas son los mismos lleva al caos de superposición de ofertas y temáticas, falsa competencia y dilapidación de recursos.

El centro de interpretación o de divulgación importante es aquel que nos permite recibir los conocimientos básicos y organizar nuest ro tiempo para recorrer los sitios patrimoniales de la manera más eficaz e inteligente posible. 
X Situada en el corazón del Parque Nacional de la Selva del Petén, la ciudad maya de Tikal (Guatemala) está formada por pirámides, templos, juegos de pelota, acrópolis, plataformas, estructuras, etc., convirtiéndola en uno de los enclaves principales de la Ruta Maya / IsABel LuQue Ceballos

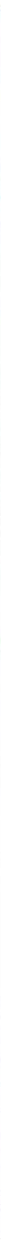

Es a través de una presentación atractiva, accesible a todos los públicos $y$, sobretodo, variada y original, por la que podemos atraer al gran publico, no sólo ser consumidores de centros y paseos en los alrededores, sino también lograr el efecto positivo en cuanto al conocimiento del patrimonio.

La clave es planificar el dónde, enlazar temáticas, complementar discursos y crear actividades relacionadas con las temáticas que emergen de los propios yacimientos, tales como la recreación de motivos históricos, costumbres, artesanado relacionado, etc.

El centro de interpretación bien planteado, mesurado y localizado en puntos claves de interés mayor puede convertirse por sí mismo en una escala favorable de la ruta y mensajero del patrimonio regional por descubrir.

A lo mejor también ha llegado el momento de repensar la comunicación del patrimonio. Ha llegado la hora de que el patrimonio cultural se convierta en materia de estudio no sólo en las universidades sino también en los colegios. Nos corresponde a nosotros, los profesionales del patrimonio, convertir ese saber en patrimonio público. 